\title{
Julien Dieudonné, Les Récits de Jean Paulhan
}

\section{Emanuele Kanceff}

\section{(2) OpenEdition}

\section{Journals}

\section{Edizione digitale}

URL: http://journals.openedition.org/studifrancesi/30738

DOI: 10.4000/studifrancesi.30738

ISSN: 2421-5856

\section{Editore}

Rosenberg \& Sellier

\section{Edizione cartacea}

Data di pubblicazione: 1 avril 2006

Paginazione: 191

ISSN: 0039-2944

\section{Notizia bibliografica digitale}

Emanuele Kanceff, «Julien Dieudonné, Les Récits de Jean Paulhan», Studi Francesi [Online], 148 (XLX I

I) | 2006, online dal 30 novembre 2015, consultato il 22 avril 2021. URL: http://

journals.openedition.org/studifrancesi/30738 ; DOI: https://doi.org/10.4000/studifrancesi.30738

Questo documento è stato generato automaticamente il 22 avril 2021.

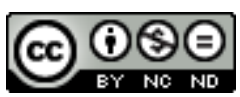

Studi Francesi è distribuita con Licenza Creative Commons Attribuzione - Non commerciale - Non opere derivate 4.0 Internazionale. 


\title{
Julien Dieudonné, Les Récits de Jean Paulhan
}

\author{
Emanuele Kanceff
}

\section{NOTIZIA}

JULIEN DIEUDONNÉ, Les Récits de Jean Paulhan, Paris, Champion, 2001 (« Littérature de notre siècle ", 16), pp. 482.

1 Paulhan è conosciuto più che altro come eminenza grigia delle lettere francesi tra il 1925 e il 1968, anno della sua morte. Questa etichetta che gli si è incollata addosso, soprattutto grazie alla copiosa corrispondenza, abbondantemente pubblicata, fa di lui, a giudizio dell'autore, un illustre sconosciuto, anche se il suo ruolo e la sua importanza nella letteratura francese del XX secolo non cessano di essere sottolineati. Soprattutto i suoi racconti sono poco letti, ignorati, introvabili, ignorati dalla ricerca univerwsitaria francofona.

2 Questo libro si propone di porre rimedio a tale stato di cose studiando, uno dopo l'altro, il contesto della narrativa di Paulhan, la storia e il vissuto come contenuto narrativo, la composizione e il ruolo dell'istante privilegiato, la situazione narratologica. La conclusione è che la poetica narratologica di Paulhan è impossibile da ridurre a qualunque scuola e pertanto originalissima. Non ci si può limitare a considerare lo scrittore come uno spettatore della modernità, poiché ha saputo offrire risposte originali a domande comuni del suo tempo, come deve fare ogni scrittore che sia impegnato nell'avventura della letteratura. 